employment in the 12 months pre and post omalizumab initiation.

Results 258 patients were enrolled from 22 UK centres (January 2012-February 2015); mean age 44.7 years ( \pm SD 14.2 ), $65 \%$ females, mean asthma duration 25.1 years $( \pm$ SD 15.1$)$ For the ITT population $(\mathrm{n}=235), 82.4 \%$ of patients were classified as responders. At 12 months, mean daily OCS dose significantly decreased by $16 \%$ from $10.3 \mathrm{mg} /$ day $( \pm 7.1)$ to $8.7 \mathrm{mg} /$ day $( \pm 8.6)(\mathrm{n}=211, \mathrm{p}<0.001)$ and $61.6 \%$ of patients stopped OCS or reduced OCS dose by $\geq 20 \%$. The mean $\left( \pm\right.$ SD) $\mathrm{FEV}_{1}$ significantly increased from $66.9 \%( \pm 19.35 \%)$ to $71.3 \%$ $( \pm 20.9 \%)$ in the 12 months post compared to pre- omalizumab initiation ( $\mathrm{p}<0.001 \mathrm{n}=118$ ). Comparing the 12 months periods prior to and following initiation of omalizumab, the mean ACT score improved from $9.8( \pm 4.3)$ to $14.4( \pm 5.7)(\mathrm{n}=162$, $\mathrm{p}<0.001)$ and the mean AQLQ score improved from 3.2 $( \pm 1.3)$ to $4.4( \pm 1.5)(\mathrm{n}=161, \mathrm{p}<0.001)$. There was a significant decrease in missed days from work/education following omalizumab initiation (12 months pre-omalizumab: 14.65 days; 12 months post-omalizumab 6.22 days with $\mathrm{p}<0.01$; $\mathrm{n}=63$ ). For 93 patients unemployed/not in education at the study start, 72 were unemployed/not in education at study end.

Conclusions The data prospectively confirm that omalizumab is associated with significant reduction in OCS use, lung function, ACT, AQLQ and days missed from work/education.

\section{S11 AUDIT OF THE SAFETY OF BRONCHIAL THERMOPLASTY USING A NATIONAL REGISTER AND HOSPITAL EPISODE STATISTICS}

1J Burn, ${ }^{1} \mathrm{AJ}$ Sims, ${ }^{1} \mathrm{~K}$ Keltie, ${ }^{2} \mathrm{H}$ Patrick, ${ }^{3} \mathrm{~S}$ Welham, ${ }^{4} \mathrm{RM}$ Niven, ${ }^{5} \mathrm{LG}$ Heaney. ${ }^{1}$ The Newcastle Upon Tyne Hospitals NHS Foundation Trust (On Behalf of the British Thoracic Society (BTS) UK Difficult Asthma Registry Participants), Newcastle Upon Tyne, UK; ${ }^{2}$ National Institute for Health and Care Excellence (On Behalf of the British Thoracic Society (BTS) UK Difficult Asthma Registry Participants), London, UK; ${ }^{3}$ British Thoracic Society (On Behalf of the British Thoracic Society (BTS) UK Difficult Asthma Registry Participants), London, UK; ${ }^{4}$ The University Hospital of South Manchester NHS Foundation Trust \& the University of Manchester (On Behalf of the British Thoracic Society (BTS) UK Difficult Asthma Registry Participants), Manchester, UK; ${ }^{5}$ Queen's University Belfast (On Behalf of the British Thoracic Society (BTS) UK Difficult Asthma Registry Participants), Belfast, UK

10.1136/thoraxjnl-2015-207770.17
Introduction and objectives NICE Guidance for bronchial thermoplasty (BT) recommends the collection of long term safety evidence. In this study we assess patient characteristics and safety outcomes using the British Thoracic Society (BTS) UK Difficult Asthma Registry (DAR) and the Hospital Episodes Statistics (HES) database.

Methods BT patient records were extracted from DAR. HES was searched for episodes from $1^{\text {st }}$ April 2011 to $31^{\text {st }}$ January 2015 with OPCS-4 code combinations known to be used for $\mathrm{BT}$; for these patients, inpatient and A\&E episodes were extracted in a second search from $1^{\text {st }}$ April 2010 to $31^{\text {st }}$ January 2015.

DAR and HES were reviewed for complications, post-procedure stay, 30-day readmissions and A\&E attendances. Using anonymised matching, records from both sources were used to calculate combined safety outcomes. As BT is usually delivered in three treatments, first, second and third BT procedures were analysed separately.

Results Details of 215 BT procedures (83 patients) were extracted from DAR and 203 procedure episodes (85 patients) were extracted from HES, of which 152 procedures (59 patients) matched. In comparison with three clinical trials (AIR, AIR2 and RISA), patients receiving BT in routine clinical practice were on average older, had worse baseline $\mathrm{FEV}_{1}$ (except for RISA trial) and had lower AQLQ scores (Table 1).

There were no significant differences in outcomes between first, second and third BT procedures; hence rates for all three procedures were combined for the matched cohort (Table 1). In the matched cohort, 27\% (41/152) of procedures were associated with a complication, readmission or A\&E attendance. This is higher than reported hospitalisation rates for the AIR2 8.4\% $(16 / 190)$ and AIR trials 7.3\% (4/55), and comparable with the RISA trial, 26.7\% (4/15).

Conclusion We present the safety of BT in routine clinical practice using combined information from a clinical register with good coverage and routine administrative data. It is likely that the clinical practice has been to treat patients with severity levels of asthma comparable to that seen in the RISA trial (high severity), compared to those used in the pivotal trial AIR2 or AIR studies, (moderate to severe), nevertheless these findings warrant further study.

Abstract S11 Table 1 Baseline characteristics and safety outcomes

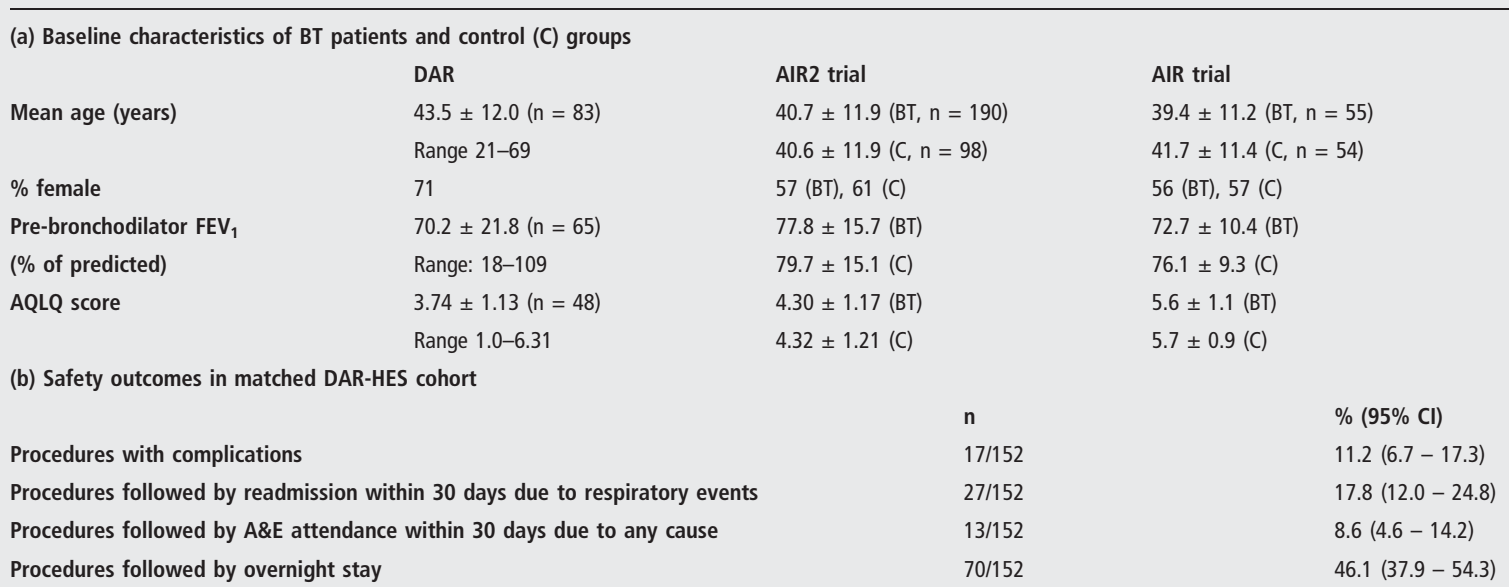

